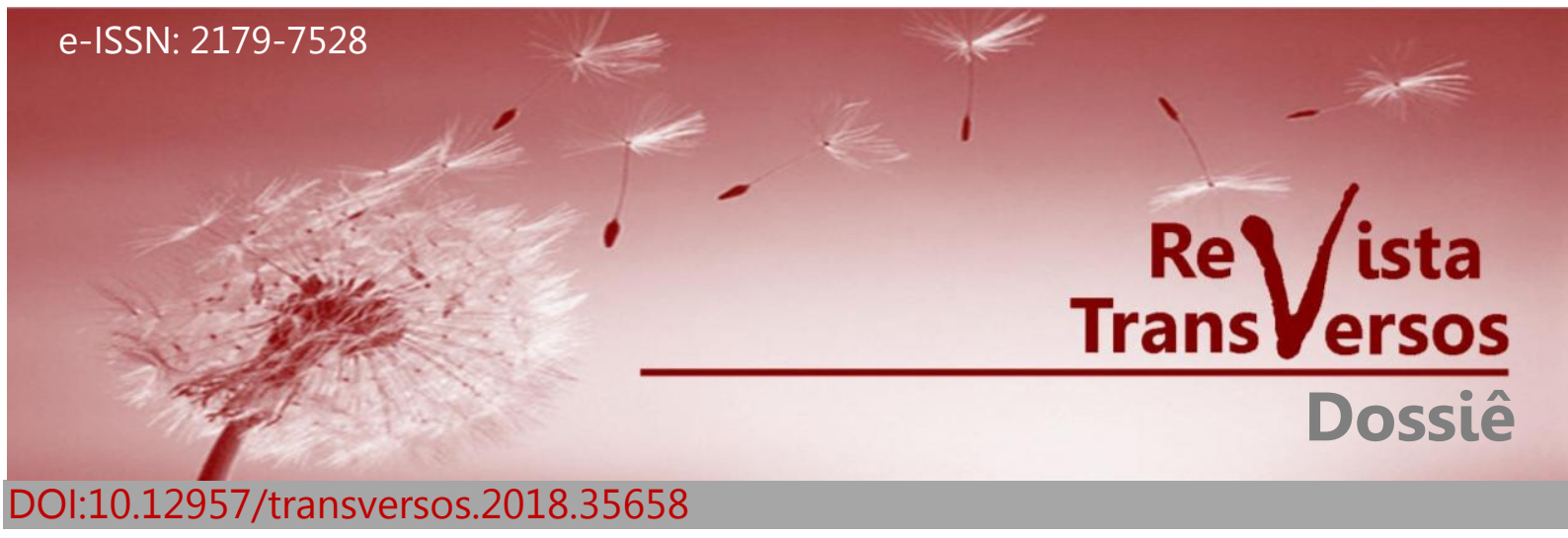

\title{
HOMO ACADEMICUS: AS AFRICANIDADES E AFRODESCENDÊNCIAS NOS CURSOS DE HISTÓRIA DA UFPI E UESPI
}

HOMO ACADEMICUS: AFRICANITIES AND AFRODESCENDECES IN THE HISTORY COURSES OF UFPI AND UESPI

\author{
Lucas Rafael Santos Costa \\ Universidade Federal do Piauí (UFPI) \\ www.lucanus@gmail.com \\ Pedro Pio Fontineles Filho \\ Universidade Estadual do Piauí (UESPI) \\ ppio26@hotmail.com
}

\section{RESUMO}

A implementação de uma lei voltada para a reformulação do currículo na contemporaneidade revela as evidências materiais do processo histórico-acontecimental de inclusão e exclusão dos atores sociais a constituírem a população nacional nas narrativas sobre a formação da nação e do povo brasileiro com suas identificações, coletividades e representações. Deste modo, este artigo se propõe a refletir, a partir da obrigatoriedade das 10639/2003 e 11645/2008, e com base nos currículos da UFPI e UESPI, em que medida estas instituições, que são os dois principais centros de pesquisa e ensino do Estado do Piauí, foram capazes de trazer ao centro da formação dos professores de História os conteúdos da História e à Cultura AfroBrasileiras, possibilitando à saída da carência de orientação (RÜSEN, 2001), no que se refere às africanidades, afro-brasilidade afrodescendências contribuindo para a valorização da diversidade étnico-racial.

Palavras-chaves:História; Ensino; Currículo; Cultura Afro-Brasileira

\section{ABSTRACT}

The implementation of a law aimed at reformulating contemporary curriculum reveals the material evidence of the historical-event process of inclusion and exclusion of social actors to constitute the national population in narratives about the formation of the nation and the Brazilian people with their identifications, collectivities and representations. Therefore, this article proposes to reflect, based on the compulsion of 10639/2003 and $11645 / 2008$, and based on the curricula of the UFPI and UESPI, to what extent these institutions, which are the two main research and teaching centers of the State of Piauí, were able to bring to the center of the formation of History teachers the contents of Afro-Brazilian History and Culture, making possible the departure from the lack of orientation (RÜSEN, 2001), as far as African, AfroBrazilian and Afro-descendents contributing to the valorization of ethnic-racial diversity.

Keywords: History, Teaching; Curriculum; Afrobrazilian Culture. 


\section{Introdução}

Em Homo Academicus, Pierre Bourdier (2011) elabora análises acerca da produção do conhecimento na França, e para isso tem sua atenção voltada para o recinto universitário. A pertinência de suas análises nos permite estabelecer, empiricamente, mapeamentos da estrutura dos espaços universitários com suas relações de poder. E, inspirados em suas ideias, propomos produzir um estudodiagnóstico sobre a inserção dos conteúdos de História da África e da História e Cultura Afro-Brasileira nas universidades públicas piauienses, a partir da lei 10639/2003 e das resoluções atinentes que a tornam obrigatória nos cursos de formação de professores de História de todo o país.

O recorte temático do presente estudo remonta à análise das Leis 10.639/2003 e 11.645/2008, no que se refere, especificamente, à História e à Cultura Afro-Brasileiras, que, com sua obrigatoriedade nos currículos e no ensino de história, implicou em mudanças significativas. Deste modo, este artigo procura refletir o que tem sido feito no nível de formação inicial e continuada de professores nas instituições de ensino superior no Estado do Piauí, com base nas competências deliberadas para o ensino da história e cultura afro-brasileira.

As legislações 10.639/03 e 11.645/08, incorporadas na redação da Lei $n^{\circ}$ 9.394/96 (LDB), têm atribuído aos sistemas de ensino municipal, estadual e federal, e em suas respectivas instituições educacionais, grandes desafios quanto ao tratamento e abordagem das temáticas da história e culturas afro-brasileiras e indígenas, bem como as relações étnico-raciais em seus espaços de ensinoaprendizagem. Essa inclusão tem suscitado incontáveis debates, não somente sobre os estudos dos afrodescendentes e indígenas, mas também sobre outros ideários maiores, como os de democracia, cidadania, identidade étnica, tendo reconhecidamente como princípio a importância e valorização destes povos na formação da sociedade brasileira, justificando a sua pertinência nas propostas curriculares em todos os níveis e modalidades de ensino.

Para investigarmos estas questões, tomamos à Universidade Federal do Piauí (UFPI) e Universidade Estadual do Piauí (UESPI) localizadas na cidade de Teresina, capital do Piauí. Tal delimitação se dá pelo fato de serem os dois maiores centros de formação de professores e por assumirem a vanguarda da produção de 
conhecimento do Estado do Piauí. O objetivo geral é compreender os caminhos delineados, por intermédio dos currículos a propósitodas africanidades e afrodescendências demandadas pelas leis.

A implementação de uma lei voltada para a reformulação do currículo escolar na contemporaneidade, nas instituições públicas e privadas de ensino básico, pode parecer um desafio que ultrapasseos limites temáticos da área histórica. Todavia, não devemos excluir que é no campo educacional que se concentram evidências materiais do processo 'histórico-acontecimental' (PÉREZ RINGUELET, 1991) de inclusão e exclusão dos atores sociais a constituírem a população nacional, com suas identificações, coletividades e representações.

Com objetivo de identificar e analisar pistas, vestígios e sinais (GINZBURG, 1989) sobre as africanidades e afrodescendências que levasse à compreensão das negociações na construção curricular, o aporte documental que dará materialidade à investigação são os Projetos Pedagógicos de Curso (PPC) dos cursos de história destas duas instituições, estrutura curricular do curso e planos de curso de disciplinas que envolvam as temáticas em questão, além de uma análise do corpo docente que se volta para estes estudos no período de 2003 a 2017. O objetivo específico é investigar as movimentações destas Instituições para se ajustarem às novas reformulações demandadas por essas legislações e pareceres.

Originalmente, a Lei Federal 10.639, de 9 de janeiro de 2003, que alterou a Lei de Diretrizes e Bases da Educação Nacional (LDB) de 1996, para incluir no currículo oficial da rede de ensino a obrigatoriedade da temática "história e cultura afro-brasileira" (BRASIL, 2003), que no ano de 2008, foi modificada dando origem auma lei mais abrangente que incorporaria os povos originários do território brasileiro. A Lei 11.645 (BRASIL, 2008), atualmente em vigor torna obrigatório nos estabelecimentos de ensino fundamental e de ensino médio, públicos e privados a "história e cultura afro-brasileira e indígena" marcando um importante avanço no caminho esboçado pela sociedade na luta antirracista.

Este aparato normativo torna-se um importante instrumento que legitima e fundamenta a (re) elaboração de novas narrativas atinentes aos afro-brasileiros e indígenas e suas heranças na formação do país, outrora tratadas como coadjuvantes e de forma alegórica frente ao protagonismo europeu (COELHO; COELHO, 2013: 
p.13). Para José Ricardo Oriá Fernandes, essa obrigatoriedade legitima "a valorização da diversidade étnico-cultural de nossa formação no sistema educacional brasileiro" (FERNANDES, 2005: p.381), ou seja, constitui a possibilidade da "construção de um multiculturalismo crítico na escola brasileira" (FERNANDES, 2005: p.384).

Com a obrigatoriedade da lei, pela primeira vez foi possível inovar no campo da educação e no ensino das relações étnico-raciais, o que significou a superação dos currículos de caráter monocultural por meio dos componentes curriculares da história da África e cultura afro-brasileira e, num segundo momento, a obrigatoriedade da história indígena,caracterizando a multiplicidade da formação da população brasileira. Essas inovações são frutos do investimento desses segmentos sociais visando promover rupturas com relação à tradição escolar fincada nos moldes do etnocentrismo europeu por meio do ensino que valorize a pluralidade de sua formação cultural. Conforme o primeiro inciso do artigo primeiro da Resolução do Conselho Nacional de EducaçãoCNE/CP 1/2004, que institui as Diretrizes Curriculares Nacionais para a Educação das Relações Étnico-Raciais e para o Ensino de História e Cultura Afro-Brasileira e Africana,

[...] as instituições de ensino superior incluirão nos conteúdos de disciplinas e atividades curriculares dos cursos que ministram, a Educação das Relações Étnico-Raciais, bem como o tratamento de questões e temáticas que dizem respeito aos afrodescendentes" (MEC, 2004: p.01).

O trecho acima mencionado chama atenção para o fato de que a inclusão da educação das relações étnico-raciais e o ensino de história e cultura afro-brasileira e africana nos cursos de história representam um significativo avanço para a formação sócio-históricas e culturais dos docentes e lança valiosos saberes para o ensino de História. Dada a relevância destes conteúdos pelo CNE que a sua implementação é definida no inciso seguinte como um critério avaliativo das condições de funcionamento do estabelecimento de ensino superior.

\section{Nas trilhas do ensinar e do saber: a atuação da UFPI}

A UFPI foi a primeira instituição de ensino superior do estado do Piauí, tendo suas origens na fundação da Faculdade de Direito em 1931. Em 1957, a Faculdade Católica de Filosofia do Piauí (FAFI) passa a ofertar três cursos destinados à formação de professores, são eles: Filosofia, Geografia e História e Letras Neolatinas (MELO, 
2006). Nesse período, o Curso de História era ligada à Geografia e sua autonomia só fora conquistada em 1971, com a extinção da FAFI e acriação da Fundação Universidade Federal do Piauí (FUFPI), em 1968, com objetivo de criar e manter a Universidade Federal do Piauí, e oficialmente instalada em 1971, que foi quando passou a ofertar de forma autônoma, o curso de Licenciatura Plena em História (MANUAL ACADÊMICO, 2017), que tem vigorado até os dias atuais.

Utilizamos como referência o Currículo 03 (PIAUÍ, 2000), como ponto de partida, que corresponde o último currículo, anterior ao ano de entrada em vigor da Lei. O Currículo 03 foi reformado no ano 2000, e passou a vigorar a partir do primeiro período de 2001. Nesta reforma foram excluídas as três disciplinas obrigatórias que permitiam discutir as africanidades e afrodescendências : História da Ásia e da África, História Social do Brasil, Expressões Folclóricas do Brasil, Cultura Brasileira ${ }^{2}$ e passou a incluir em sua grade curricular, na condição de optativas designadas como Tópicos Especiais $^{3}$ as seguintes disciplinas: Tópicos Especiais III - História, Trabalho, Escravidão (60h); Tópicos Especiais VII - História da África e da Ásia (60h); Tópicos Especiais VIII - Brasil: História e Movimentos Sociais (60h). Com a reforma estasdisciplinas passaram por uma reformulação em suas nomenclaturas e foram submetidas à condição de optativas.

A disciplinas que discutiam temas relacionado a África e a cultura afrobrasileira nos seus diversos campos de investigação passaram por um processo de redimensionamento da categoria de obrigatórias para optativas. A grande novidade foi a disciplina Movimentos Sociais voltada para o protagonismo de determinados segmentos da sociedade civil na construção da democracia brasileira na conquista de direitos políticos e sociais. Outra reforma curricular do curso de Licenciatura em História da UFPI, passou a vigorar a partir de $2012^{4}$ (PIAUÍ, 2011), permanecendo em

\footnotetext{
${ }^{2}$ As disciplinas Expressões Folclóricas do Brasil e Cultura Brasileira eram ofertadas para outros cursos, sobretudo, para os cursos de Comunicação Social, Letras e Enfermagem. Contudo, mesmo com a exclusão delas na reforma, estas disciplinas ainda, continuaram esporadicamente a serem ofertadas para estes cursos.

${ }^{3} \mathrm{~A}$ execução curricular para as disciplinas designadas como Tópicos Especiais eram de ementário aberto e deveriam passar e ser aprovadas pelo Colegiado do Curso de História.

${ }^{4}$ Comissão de Elaboração do Projeto Político Pedagógico: Antônio Fonseca dos Santos Neto, Elizangela Barbosa Cardoso, Francisco Alcides do Nascimento, Maria do Socorro Rangel, Robério Américo do Carmo Souza
} 
vigor até o fim do recorte temporal investigado. Esta última passou por alguns ajustes no ano de 2016.

Tomando por base o atual currículo que funciona de acordo com o Projeto Pedagógico aprovado em 2011 e ajustado em 2016, pode se verificar a presença de três disciplinas que carregam temáticas sobre história da África e cultura afrobrasileira, são elas: História da América Afro-portuguesa, Cultura Afro-Brasileira e História da África. Sendo que apenas a História da América Afro-portuguesa é obrigatória e desfruta de uma regularidade na oferta, enquanto que as demais compõem a categoria de disciplinas optativas.

A disciplina "História da América Afro-portuguesa"possui carga-horária de $60 \mathrm{~h}$ e conforme o fluxograma do curso ela é ofertada no segundo período. Essa disciplina trata da expansão marítima europeia portuguesa, exploração, colonização e a participação africana na colônia. Conforme o PPC, a ementa seria a seguinte:

[...] análise da produção historiográfica. A expansão marítima europeia e o descobrimento do Brasil. A exploração e colonização e sua relação com o meio ambiente. A sociedade colonial: vida, imaginário, comportamento e transgressão. As invasões francesas. A ocupação holandesa em Pernambuco e Maranhão, os movimentos nativistas. A transmigração da família real. $O$ ensino da história da colonização portuguesa e da participação africana na escola básica (UFPI, 2011: p. 49).

Ainda que o "afro" venha explicitado no título da Disciplina é possível identificar a valorização dos conteúdos referentes à expansão marítima europeia, descobrimento do Brasil e sobre a sociedade que se formou com essas bases e, somente no final do ementário, como que em uma espécie de fôlego final, aparece como conteúdo o "ensino da participação africana na escola básica", uma participação que não é especificada. O termo "participação" aparentemente, também escamoteia a ideia de "atuação". Ou seja, o negro ainda como coadjuvante. Nas narrativas sobre a formação da nação e do povo brasileiro é lugar comum o protagonismo da Europa, enquanto que os povos africanos e indígenas assumem o papel de meros coadjuvantes (COELHO; COELHO, 2013). Um relevante debate seria discutir e compreender os planos de curso dos professores desta Disciplina. O branco colonizador conduz todo o processo de formação das primeiras sociedades nacionais, definindo as bases civilizatórias mitigando as demais culturas. A 
bibliografia ${ }^{5}$ de referência destaca a quantidade de obras voltadas para o tema da África, africanidades e afrodescendências, porém os textos propostos não trabalham com ensino de história da África.

A optativa "Cultura Afro-Brasileira"6, com duração de (60h), apresenta a seguinte ementa:

[...] a historiografia da cultura africana. O conceito de cultura afro-brasileira. Diversidade sociocultural das etnias africanas que imigraram para América Portuguesa. Contribuições africanas na construção da cultura brasileira. A cultura afro-brasileira como tema para o ensino na escola básica (UFPI, 2011: p. 55).

Esta é uma disciplina que tem potencial para atender plenamente as propostas esboçadas pela lei. O mesmo vale para a disciplina "História da África"7,

${ }^{5}$ A Bibliografia básica para esta disciplina é formada por ALENCASTRO, Luis Felipe de. O trato dos viventes: formação do Brasil no Atlântico Sul. São Paulo: Companhia das Letras, 2000; ARAÚJO, Emanuel. O Teatro dos Vícios: transgressões e transigência na sociedade urbana colonial. Rio de Janeiro: José Olympio, 1993; DEL PRIORI, Mary. Ao sul do corpo: condição feminina maternidade e mentalidades no Brasil Colônia. Rio de Janeiro: José Olympio/Edunb, 1993; O Príncipe Maldito. Rio de Janeiro: Editora Objetiva, 2007; LYRA, Maria de Lourdes Viana. A utopia do poderoso império. Portugal e Brasil: bastidores da política, 1798-1822. Rio de Janeiro: Sette Letras, 1994; MALERBA, Jurandir. A corte no exílio. São Paulo: Companhia das Letras, 2000; SOUZA, Laura de Mello. O Diabo na terra de Santa Cruz. São Paulo: Companhia das Letras, 1986; VILLALTA, Luiz Carlos. 1789 - 1808. O Império luso-brasileiro e os brasis. São Paulo: Companhia das Letras, 2000; Bibliografia Complementar: MELLO, Evaldo Cabral de. Rubro Veio. O imaginário da Restauração Pernambucana. Rio de Janeiro: Nova Fronteira, 1986; SCHWARTZ, Stuart. Segredos internos: engenhos e escravos na sociedade colonial 1550 -1835. São Paulo: Companhia das Letras, 1990; SOUZA, Laura de Mello. (org.) História da vida privada no Brasil. Cotidiano e vida privada na América Portuguesa. São Paulo: Companhia das Letras, 1997.

${ }^{6}$ A Bibliografia básica para esta disciplina é formada por: ABREU, Marta. O Império do Divino: Festas Religiosas e Cultura Popular no Rio de Janeiro, 1830-1900. Rio de Janeiro: Nova Fronteira, 2000; BASTIDE, Roger. As religiões africanas no Brasil. São Paulo: EDUSP/Pioneira, 1971; BARROS, José D'Assunção. A construção social da cor: diferença e desigualdade na formação da sociedade brasileira. Petrópolis: Vozes, 2009; CANEDO, Letícia Bicalho. A Descolonização da Ásia e da África. São Paulo: Atual, 1986; CARNEIRO, Edison. Candomblés da Bahia. 5 ed., Rio de Janeiro: Civilização Brasileira, 1977; DEL PRIORE. Mary e PINTO VENÂNCIO, Renato. Ancestrais. Uma introdução à história da África atlântica. Rio de Janeiro, Elsevier, 2004; FLORENTINO, Manolo. Em Costas Negras: uma história do tráfico de escravos entre a África e o Rio de Janeiro. São Paulo: Companhia das Letras, 1997; FREYRE, Gilberto. Casa grande \& senzala. $3^{a}$ edição, São Paulo: Anita, 1995; HEYWOOD, Linda M. Diáspora negra no Brasil. São Paulo: Contexto, 2008; HOBSBAWM, Eric J. A era dos impérios 1875-1914. Rio de Janeiro: Paz e Terra, 1988; Bibliografia Complementar: BORDIEU, Pierre; BORDIEU, Marie-Claire. O camponês e a fotografia. In: Revista Sociologia Política, Curitiba, 26, p. 31-39, jun. 2006; CHARTIER, Roger. História Cultural: entre práticas e representações. Rio de Janeiro: Bertrand Brasil, 1990; CHOAY, Françoise. A alegoria do patrimônio. São Paulo: Estação Liberdade, 2001; CLIFFORD, James. A Experiência Etnográfica. Antropologia e Literatura no século XX. Rio de Janeiro: Editora da UFRJ, 2002.

${ }^{7}$ A Bibliografia básica para esta disciplina é formada por: BASTIDE, Roger. As religiões africanas no Brasil. São Paulo: EDUSP/Pioneira, 1971; BARROS, José D'Assunção. A construção social da cor: diferença e desigualdade na formação da sociedade brasileira. Petrópolis: Vozes, 2009; CANEDO, Letícia Bicalho. A Descolonização da Ásia e da África. São Paulo: Atual, 1986; CARMO, João Clodomiro do. O que é candomblé. Coleção Primeiros Passos. São Paulo: Brasiliense, 2006; CARNEIRO, Edison. Candomblés da Bahia. $5^{a}$ edição, Rio de Janeiro: Civilização Brasileira, 1977; DEL 
com duração de 60 horas-aula e que, em sua ementa define "Cultura e sociedade africanas antes da colonização europeia. Expansão marítimo-comercial e colonialismo. Imperialismo e dependência. A 'construção' do Terceiro Mundo. Descolonização da África. A África na atualidade" (UFPI, 2011: p. 55).A partir do PPC e dos quadros de ofertas é possível constatar que as disciplinas que trazem a centralidade da África e da cultura afro-brasileira, em grande medida, acabam caindo no caráter optativo, fato que indica que tal oferta ficava na dependência de elementos estruturantes como o interesse da coordenação do curso, da disponibilidade do quadro de professores, e de professores que tenham interesse em ministrá-la, além da demanda dos alunos, isto é, não desfruta de uma periodicidade e fica mais dada ao caráter do "acaso" que consiga congregar tais elementos.

Conforme o Manual acadêmico de 2017, o curso de história da UFPI, campus Petrônio Portella em Teresina, possui apenas um professor que atua diretamente com as temáticas de africanidades e da "escravidão no Brasil do século XIX" Todavia, o fato destas especialidades não estarem expressas no documento não quer dizer, necessariamente, que não estejam sendo discutidas em sala de aulas do curso, nos espaços acadêmicos e por outros professores. Apesar do caráter optativo destas disciplinas, é inegável os seus efeitos no corpo docente e na estruturação dos cursos dado o reconhecimento das mudanças que trazem à baila a importância da África na formação do Brasil.

PRIORE. Mary e PINTO VENÂNCIO, Renato. Ancestrais. Uma introdução à história da África atlântica. Rio de Janeiro, Elsevier, 2004; ENDERS, Armelle. Histoire de l'Afriquelusophone. Paris, Chandeigne,1994; FLORENTINO, Manolo. Em Costas Negras: uma história do tráfico de escravos entre a África e o Rio de Janeiro. São Paulo: Companhia das Letras, 1997; FREYRE, Gilberto. Casa grande \& senzala. $3^{a}$ edição, São Paulo: Anita, 1995; HERNANDEZ, Leila. Movimentos de resistência na África. In Revista de História, São Paulo, n.141, 20 semestre, 1999; HERNANDEZ, Leila. A África na sala de aula: visita à história contemporânea. São Paulo: Selo Negro, 2005; HOBSBAWM, Eric J. A era dos impérios 1875-1914. Rio de Janeiro: Paz e Terra, 1988; MILLER, Joseph C. "África Central durante a era do comércio de escravizados, de 1490 a 1850." In: HEYWOOD, Linda M. Diáspora negra no Brasil. São Paulo: Contexto, 2008; PINSKY, Jaime. As Primeiras Civilizações. Editora Atual. São Paulo, 1987; POLIAKO, Léon. De Maomé aos Marranos. História do Anti-Semitismo. Editora Perspectiva. São Paulo, 1984; SAID, Edward W. Orientalismo: O Oriente como invenção do Ocidente. Companhia das Letras, São Paulo, 1990; SILVA, Alberto da Costa. A África explicada aos meus filhos. Rio de Janeiro: Agir, 2008.

${ }^{8}$ Trata-se do professor Dr. Jonhy Santana de Araújo, que possui pesquisas na área da História Social, sobretudo guerra, História do Piauí e Ensino de História. Todavia, tem-se outros professores que desenvolvem pesquisas e orientam trabalhos, tanto no campus de Teresina, bem como nas demais campus do interior, além de receber contribuições de docentes de outros cursos como do professor Dr. Solimar Oliveira Lima. 


\section{Entre o nacional e o local: o papel da UESPI}

A Universidade Estadual do Piauí, assim como a UFPI, caracteriza-se como uma instituição pública de ensino superior, todavia estadual com sede na capital Teresina. Ela foi criada em 1984, com a sua entidade mantenedora a Fundação de Apoio ao Desenvolvimento da Educação do Estado do Piauí - FADEP ${ }^{9}$. No ano de $1985^{10}$, essa instituição oferecia os cursos de Pedagogia, Ciências com habilitação em Matemática e Biologia, Letras com habilitação em Português e Inglês e Literaturas e Administração. No ano de 1993, por intermédio de decreto federal, foi autorizada a expansão da universidade com oferta de diversos cursos pelas cidades do interior do estado. Esta expansão foi fundamental para o desenvolvimento da educação no estado do Piauí por permitir a formação de pessoas qualificadas sem a necessidade de irem à capital, possibilitando a democratização do ensino.

O curso de Licenciatura Plena em História ${ }^{11}$ da UESPI funciona em regime de bloco fechado. Entre as décadas de 1990, e até o ano de 2017,passou por algumas reformas curriculares nos anos de 1995, 2006, 2012, 2015, este último em vigência até 2018. A proposta de 2006, em relação à anterior, apresenta algumas mudanças como a gestão curricular das disciplinas formada por quatro áreas de conhecimento $^{12}$, com nove eixos que continham as chamadas disciplinas temáticas baseado no sistema de pré-requisito.

Outra mudança no que se refere ao objeto de pesquisa é a introdução de "História da África e da Ásia" de cunho teórico como disciplina obrigatória no quinto bloco, com carga-horária de 60 horas-aula. Ela fazia parte da Área do Conhecimento I (História e Conteúdo) - Eixo Temático I, assim como a disciplina "História da Cultura Brasileira", oferecida no segundo bloco, também com 60 horas-aula. Disciplina inserida no âmbito do currículo da UESPI na área do conhecimento II e eixo temático história e teorias. Conforme o PPC de 2006, o ementário e objetivos são definidos por bloco e um dos objetivos específicos para quinto bloco seria "reconhecer a

\footnotetext{
${ }^{9}$ Ver PIAUÍ. Lei Estadual n 3.967.

${ }^{10}$ Ver BRASÍLIA. Decreto Federal n 91.851.

${ }^{11} \mathrm{O}$ curso é, atualmente, ofertado de forma presencial nos seguintes campi: Teresina (Torquato Neto e Clóvis Moura), São Raimundo Nonato, Floriano, Parnaíba, Oeiras e Campo Maior.

${ }^{12}$ Área do Conhecimento I (História e Conteúdo), Área do Conhecimento II (História e Teorias), Área do Conhecimento III (História e Pesquisa), Área do Conhecimento IV (História e os Fundamentos Pedagógicos).
} 
importância da história da África e da Ásia para compreensão da história" (UESPI, 2006: p.57). A Ementa da disciplina propõe "reflexão sobre o conceito de Oriente $x$ Ocidente; Processo de formação histórica e discursiva da África e Ásia; Questões acerca dos ideais nacionalistas na África e na Ásia"13.

Em 2012, houve uma nova reforma e a disciplina que leva África em sua nomenclatura passa por alguns ajustes em relação ao PPC anterior de 2006. Ela perde o objetivo específico para o bloco quinto bloco supracitado que possuía como requisito reconhecer a importância da história da África e da Ásia na compreensão da história. Deste modo não há mais nenhum objetivo específico que trate ou faça menção ao objetoÁfrica e suas subcategorias. Quase a totalidade dos objetivos são voltados para o ensino de história dada ao caráter das disciplinas ofertadas no bloco $^{14}$. A disciplina passou para o sétimo período, o que é mantido até hoje, ampliando sua bibliografia básica ${ }^{15}$. $\mathrm{O}$ que em parte, se justifica pelo aumento das

${ }^{13}$ A bibliografia apresentada para a disciplina "História da África e da Ásia" conforme o PPC, 2006 é: APPIAH, Kuane Anthony. Na casa de meu pai: a África na filosofia da cultura. Rio de Janeiro. Contraponto. 1997; BRAUDEL, Fernand. Gramática das Civilizações. São Paulo. Martins Fontes. 1959; CANEDO, Letícia Bicalho. A descolonização da Ásia e da África. $12^{a}$ edição. São Paulo; GIORDANI, Mário Curtis. História da Ásia anterior ao descobrimento. Petrópolis, Rio de Janeiro. Ed. Vozes. 1996.; GILROY, Paul. O Atlântico Negro: modernidade e dupla consciência. São Paulo. Ed.34. Rio de Janeiro. Universidade Cândido Mendes. Centro de Estudos Afro-Asiáticos. 2001.; GALLES, Ricardo e SOARES, Mariza de Carvalho. Episódios de história afro-brasileira. Rio de Janeiro. DP e A/FASE,2005; LINHARES, Maria Yedda. A luta contra a metrópole (Ásia e África).6a ed. São Paulo. Brasiliense. 1993.; $O$ oriente médio e o mundo árabe. Col. Tudo é História. $3^{a}$ ed. São Paulo. Brasiliense. 1992.; LIMA, Maria de Nazaré (org). Escola Plural a diversidade está na sala de aula.formação de professoras em história e cultura afro-brasileira. São Paulo. Cortez. Brasília. UNICEF. Salvador - BA. CEAFRO.2005; OLIVER, Roland. A experiência africana.da pré-história aos dias atuais. Rio de Janeiro. Jorge Zahar Editora. 1994.; PAULA, E. Simões de. In: Introdução ao estudo da História da África. In: Revista de História.Vol. XXV. Ano XIII. No 52. 1962.; PLATÃO, Eugênio de Carvalho. Neocolonialismo.a expansão imperialista do Séc. XIX. Col. Tudo é História. São Paulo. Brasiliense. 1994.; SAID, Edward. Orientalismo:o oriente como invenção do ocidente. São Paulo. Companhia das Letras. 1990.

${ }^{14}$ Neste bloco são ofertadas as seguintes disciplinas História Contemporânea II (90h); Estágio Supervisionado II (100h); Monografia I (60h); Prática Pedagógica VII (50h) e História da África e da Ásia (60h), justificando os objetivos serem, em sua maioria, voltadas para o ensino e pesquisa, no entanto, há um objetivo especifico que argumenta "Obter conhecimentos acerca do mundo contemporâneo".

${ }^{15}$ Foram acrescentadas as referências bibliográficas básicas: DIRETRIZES CURRICULARES NACIONAIS PARA A EDUCAÇÃO DAS RELAÇÕES ÉTNICO-RACIAIS E PARA O ENSINO DE HISTÓRIA E CULTURA AFRO-BRASILEIRA E AFRICANA: Disponível em http://portal.mec.gov.br/index.php?option=com_content\&view=article\&id=12988: pareceres-eresolucoes-sobre-educacao-das-relacoes-etnico-raciais\&catid=323:orgaos-vinculados $>$.Acesso em 23 de julho de 2012.; MOORE, Carlos. A África que incomoda: sobre a problematização do legado africano no quotidiano brasileiro. São Paulo. Ed. Nandyala. 2008.; WALDMAN, Maurício e SERRANO, Carlos. Memória D 'África: a Temática africana em sala de aula. São Paulo. Ed. Cortez, 2007. 
pesquisas dos professores, pelaoferta e acesso a novos livros e textos sobre o referido recorte temático.

No PCC de 2015 as disciplinas em geral passam a descrever as competências e o cenário de aprendizagem. A "História da África e da Ásia" por exemplo definiria um ementário mais abrangente, inclusive com referência à própria legislação que torna seu ensino obrigatório:

A África como objeto de Estudo; O continente e sua geografia; Política, religião e economia: a África Saariana e a expansão do Islã; Escravidão, comércio trans/intercontinental: homens e mercadorias; O fim do tráfico de escravos; O contexto africano no século XIX; Ocupação europeia e resistência; Os diferentes colonialismos; Ideologias anticoloniais: panafricanismo e negritude; Os nacionalismo africanos e a descolonização; As independências; A África atual; Ensino de História da África (lei 10.639/03); Tópicos de História da Ásia (UESPI, 2015: p.82).

O que se pode observar sobre a disciplina e a ementa é uma enorme concentração de conteúdos e possibilidades de problematizar dois continentes e culturas completamente diferentes em uma única disciplina de sessenta horas. Essa concentração estimula um rico debate histórico e cultural sobre os dois continentes. Das quatro competências proposta três são destinados ao continente africano e à história africana ${ }^{16}$ e somente uma ao trato da realidade histórica da Ásia ${ }^{17}$. Em tese a orientação para a divisão dos conteúdos deve ser de 30 horas de África e 30 de Ásia, contudo, esse equilíbrio de horas-aula dificilmente é cumprido a começar pelas orientações das competências que já estão desequilibradas. A bibliografia básica foi

\footnotetext{
${ }^{16}$ São i) analisar os diferentes discursos historiográficos construídos em torno do continente africano; ii) compreender a história africana e seus desdobramentos no tempo presente; iii) fomentar a prática de ensino da história da África e sua intersecção na cultura brasileira, tendo como base uma exigência legal (LDB).

${ }^{17}$ Aprofundar conhecimentos acerca da realidade histórica da Ásia e suas possíveis inter-relações com o ocidente nos diferentes campos (cultura, História e demais).
} 
enxugada ${ }^{18}$, além da apresentação de quatro competências ${ }^{19}$ almejadas ao fim da disciplina.

O que se pode destacar é que o curso de História da UFPI sediado na capital, mesmo com um número reduzido de professores especializados nas temáticas tem articulado ações que provocam debates sobre o desenvolvimento das novas disciplinas. Isso pode ser verificado nas configurações das últimas grades curriculares que já apresentam história da África e cultura afro-brasileira. Já a UESPI embora possua um corpo docente de especialistas no trato destas questões, isso ainda não se refletiu na criação de disciplinas específicas.

Essas descrições foram feitas com base nos PPC da formação inicial e presenciais nos cursos de História propostos na capital Teresina. Além das modalidades como o Programa Nacional de Formação de Professores da Educação Básica (PARFOR) e cursos à distância (EAD). No caso da UESPI, estas duas modalidadesseguem a mesma matriz curricular do curso tradicional, a diferença é a disciplina específica de Introdução à Educação à Distância. Estas instituições também desempenham um importante papel na formação de professores no contexto das pós-graduações,com destaque para os cursos de qualificações profissionais como especializações e de eventos no campo da história e áreas afins.

No Piauí, aUniversidade Federal do Piauí (UFPI), por meio do Centro de Educação Aberta e à Distância (CEAD) durante o biênio 2014-2015 no município deTeresina, ofereceu os seguintes cursos de Especialização: Política de Promoção da Igualdade Racial da Escola, Gestão de Políticas Públicas em Gênero e Raça, Gêneroe Diversidade na Escola. Com 50 vagas cada um, destinadas a profissionais da

\footnotetext{
${ }^{18}$ Bibliografia Básica: APPIAH, Kwame Anthony. Na Casa de Meu Pai: A África na filosofia da cultura. Rio de Janeiro: Contraponto, 1997.; KI-ZERBO, J. (org.). Coleção História Geral da África em português. Brasília: UNESCO, Secad/MEC, UFSCar, 2010.; SEGRILLO, Angelo. (org). História Revisionista da Ásia e Outros Ensaios do Laboratório de Estudos da Ásia da USP. Cenegri Edições, 2013. Bibliografia Complementar: COSTA E SILVA, Alberto da. A enxada e a lança: a África antes dos portugueses. $2^{a}$ edição Rio de Janeiro: Nova Fronteira, 1996; GILROY, Paul. O Atlântico Negro: Modernidade e dupla consciência. Rio de Janeiro: Editora 34, 2001; HERNANDEZ, Leila Leite. A África na Sala de Aula: visita à história contemporânea. São Paulo: Selo Negro, 2005; YAMASHIRO, José. Pequena História do Japão. Editora Herder. São Paulo, 1964; SAID, Edward. Orientalismo - o Oriente como invenção do Ocidente. Trad. RosauraEichenberg. Coleção Companhia de Bolso. São Paulo: Companhia das Letras, 2007.

${ }^{19}$ Analisar os diferentes discursos historiográficos construídos em torno do continente africano; compreender a história africana e seus desdobramentos no tempo presente; fomentar a prática de ensino da história da África e sua intersecção na cultura brasileira, tendo como base uma exigência legal (LDB).; aprofundar conhecimentos acerca da realidade histórica da Ásia e suas possíveis interrelações com o ocidente nos diferentes campos (cultura, História e demais);
} 
educação básica da rede pública de ensino. Tais cursos representam um desdobramento da institucionalização do movimento negro que chama atenção para a necessidade de saberes epistemológicos das relações étnico-raciais, na formação docente para a diversidade, conduzindo a promoção da igualdade pela via do ensino.

A expectativa expressa nesta política de qualificação é que o professor possa exercer um papel de multiplicador. A formação de uma consciência histórica que leva a processos de identificações, neste caso exerce uma ação determinante. Um comprometimento que instigue a levar o debate para a sala de aula, possibilitando rupturas com as narrativas tradicionais e silenciamentos. O que implicaria diretamente na real efetivação das práticas deconteúdos referentes à história e cultura afro-brasileira de forma ressignificadas. Neste caso, para além de políticas identitárias o saber histórico deve conduzir para a problematização da questão da cidadania e garantia de direitos sociais. Neste quesito, Junia Pereira destaca:

O trabalho escolar não comporta neutralidades. Se, por um lado, a
promulgação desta legislação se realizou em contexto de democratização
social e de luta assertiva pela conquista de direitos de cidadania no país, ela
se vincula a contextos escolares diversos - por suposto, não há como
predizer que a recepção e a prática desta legislação ocorrerão de forma
homogênea ou mesmo da maneira como prescrita ou prevista. Todos
sabemos o quanto há de ressonância - ou de distância - entre o conteúdo
de uma lei e a sua prática nas mais variadas circunstâncias, sobretudo no
ambiente escolar. A recepção é terreno de autonomias. Neste campo haverá
usos diferenciados, também renovadas e mutáveis interpretações (PEREIRA,
2011: p.149).

Concordamos com a análises, no sentido de que tal Lei não representa em si a garantia de sua exequibilidade. A mesma incide no mosaico cultural das negociações, ideologias hegemônicas historicamente enquadradas na educação escolar brasileira. Na UESPI, o curso de Especialização na modalidade EAD em História e Cultura Afro-Brasileira e Africana se destina, principalmente, para o público que já atua no ensino Estadual e Municipal. Conforme a proposta de 2013, deve funcionar em três turnos e possuir abrangência geográfica nos municípios de Picos, Simplício Mendes, Piracuruca, Campo Maior (UESPI, 2013), tendo como objetivo geral:

A proposição do curso História e Cultura Afro-Brasileira e Africana tem como objetivo geral contribuir para a efetivação da Lei de Diretrizes e Bases da Educação nos seus artigos 26A e 79B, que dizem respeito a obrigatoriedade do ensino de história e cultura afro-brasileira e africana na educação básica. Bem como das Diretrizes Curriculares Nacionais para a Educação das Relações Étnico-raciais e para o Ensino de História e Cultura Afro-Brasileira e Africana (UESPI, 2013: p.13). 
Entre os cursos tradicionais, modalidade a distância e pós-graduações nas duas universidades no Estado do Piauí, é possível verificar que onde mais se tem avançado no tocante às questões de africanidades é nos cursos de especialização. Esse estudo-diagnóstico confirma o que diz Benjamim eGuimarães quando se referem à formação continuada, afirmando que ela "torna-se basilar para a implementação da obrigatoriedade do estudo da história e da Cultura Africana e Afro-brasileira, tendo em vista a formação inicial considerada lacunar ou mesmo insatisfatória neste campo" (PAULA; GUIMARAES, 2014: p.445).

Mônica Lima (2000), entre outros, considera a formação de professores como um dos grandes empecilhos a implementação da Lei. Para ela, essa formação deficiente é fruto de "séculos de desconhecimento e distanciamento intelectual", o que nos permite indagar- a partir de suas palavras -"queHistória será esta a ser apresentada, se a maioria dos professores em sala não teve contato com ela?" (LIMA, 2000: p. 163). A formação histórica brasileira fundamentada na matriz europeia, em especial na francesa, não reconhece na África e sua relevância, reforçando o seu desconhecimento. Questão latente na educação brasileira que precisa ser problematizada o que, ainda segundo a autora, conduz a uma outra profunda discussão:

Não há como recuperar a africanidade de nossa História sem recuperar a própria História da África. E neste caso, trata-se de construir referências, de recuperar memória, de trazer à tona tudo aquilo que não encontrou estímulo para sedimentar-se na cultura individual e coletiva sobre $\mathrm{O}$ significado das relações com a África na nossa História (LIMA, 2000: p. 164).

É fundamental destacar a ancestralidade africana para a contemporaneidade na história do Brasil e do mundo. Os aspectos legais não são os únicos elementos que ponderam a importância da história da África - "conhecer a história da África é um caminho para entendermos melhor a nós mesmos" (LIMA, 2010: p. 25). Neste sentido, acrescentamos as palavras do historiador Joseph Ki-Zerbo, que introduz a coleção sobre África ${ }^{20}$, dizendo que "a África tem uma história" (KI-ZERBO, 2010: p. 31) e para ele apropriar-se dessa história representa um ato de tomada de

\footnotetext{
${ }^{20}$ A Coleção História Geral da África constitui-se como uma coletânea de estudos sobre a História da África. Ela é realizada, essencialmente por pesquisadores africanos e é dividida em oito volumes. Disponível http://portal.mec.gov.br/index.php?option=com_\%20content\&view=article\&id=16146. 
consciência. Conclui chamando atenção para o fato que ela deve ser reescrita, não no sentido de uma história-revanche, mas de mudar de perspectiva e criar em todos uma consciência autêntica.

A partir do conceito de tomada de consciência de Ki-Zerbo e na perspectiva do que propõe Mônica Lima, entendemos que a África, ou pelo menos a parte que nos faz referência e que une o país ao continente, serve como um caminho para entender a nós mesmos. Constatamos, entretanto, que esta história tem passado por um processo de reformulação nos currículos das universidades do Piauí e em todo o corpo docente formado por esses canais de construção de conhecimentos o que instiga uma maior tomada de consciência.

Seria possível apropriar-se da história? Jack Goody, entende que sim no seu livro O Roubo da história:como os ocidentais se apropriaram das ideias e invenções do Oriente(GOODY, 2008). Ele problematiza a associação das narrativas das sociedades europeias com a história da humanidade estabelecendo largas reflexões de como os europeus se apropriaram das ideias e invenções do Oriente ao longo da história. Para o autor, o forjamento da "excepcionalidade europeia" foi possível, por intermédio, do domínio da escrita etnocêntrica da história ao longo da história.

Quando o assunto é África, os espaços educativos ainda vivem sob o imperativo das ausências e do exótico: ausência de especialistas, leituras específicas, de referências e isso caracteriza um iminente perigo da permanência de uma história única e propagação de uma imagem depreciativa da África e do africano, fundada no desconhecimento da sua história. Sobre isso, Nilma Lino Gomes argumenta:

\footnotetext{
A ignorância tem sido ao longo da história da humanidade um campo fértil para a propagação de preconceitos. Dessa forma, a ignorância sobre a África e sobre a trajetória de ação, luta, resistência e efervescência cultural e política da comunidade negra brasileira tem sido empecilhos para a construção de uma educação antirracista e que caminhe na perspectiva diversidade (GOMES; AMÂNCIO, 2008: p.154).
}

Nos cursos de História destas duas instituições, que têm como objetivo formar pessoas para exercerem função de historiador e de professor de história, que são dois lados de uma mesma moeda, pode-se concluir que o problema estaria na formação deficiente do professor que o mantém, mesmo sem saber, imerso na "carência de orientação",no sentido de JörnRüsen(2001). O que o leva a transformar, ainda que inconscientemente, o discurso historiográfico numa visão particularizante 
da história. O curso serviria para, a pretexto das legislações, pensar sobre como estas instituições tem colaborado para a passagem, ou não, da "carência de orientação" à "consciência histórica". O que se pode aferir é que a carência na formação teórica e prática acaba por dar continuidade a um ciclo de desconhecimento sobre a importância da África na formação do Brasil.

Na perspectiva defendida pela legislação, deve ser dada atenção singular à formação docente. Afinal, a operacionalização desta lei, passa pela criação de condições,o que gera uma nova demanda - oferta de cursos e materiais pedagógicos para que haja o gerenciamento qualificado de toda essa composição em sala de aula. Com base na historiografia e no conhecimento da história do ensino de história e na atuação dos movimentos sociais que mobilizam essas demandas, torna-se evidente que não se trata simplesmente de incluir o ensino de história da África e cultura afrobrasileira. Não é puramente a questão da inserção do negro e do índio no ensino. Para Lima, "o que está em jogo é bem mais que a nossa competência profissional, é o nosso compromisso com um país mais justo e com um mundo melhor para todos e todas" (LIMA, 2010: p.28). Enfim, o que ainda está em jogo é algo muito amplo, são as nossas referências de passado e tem a ver com o que a gente pensa enquanto projeto de sociedade. São questões profundas nas quais a lei é apenas um elemento do complexo do debate que precisa ser discutido pela sociedade, não somente nos espaços escolares mais nas ruas, nas praças, nas salas, nas igrejas ou mesmo nos terreiros. Os centros de formação, sejam eles a escola ou universidades, podem legitimar determinados modos de ver e fazer, como também podem e devem questioná-los. Assim, a memória desviante historicamente propagada, fruto das relações de poder que deslocam essas memórias como minimamente incapazes de assumir qualquer tipo de protagonismo ou poder criativo, seja qual for o âmbito cultural, relegando, na maioria das vezes, ao silêncio quando não o lugar de inferioridade na hierarquia social e cultural como tanto tem denunciado o movimento negro.

Estas duas instituições que atuam diretamente na formação inicial de professores e também na programação e oferta de cursos de formação continuada como cursos de atualização profissionais e especializações estabelecendo um viés legitimador para esta produção intelectual da universidade piauiense em torno das africanidades. Uma oportunidade única de promover, conduzir e protagonizar um movimento de rupturas com modelos tradicionais que legitimam, justificam e 
hierarquizam a sociedade, que gera subprodutos na cultura. Seu protagonismo possibilita abrir caminho para inovar epistemologias, saberes e fazeres que valorizem o outro, numa cultura do respeito e reconhecimento das suas diferenças.

O futuro a que se propõe a legislação nacional, e os anseios de novos parâmetros de sociedade, dependem da legitimação dos espaços acadêmicos das universidades, da formação de professores e da intervenção destes atores no mundo. Sua ação pode aliar-se à manutenção das estruturas dominantes ou pode levar a desconstruções e fissuras. A verificação dos currículos destas universidades tem demonstrado que pouco tem avançado no debate das africanidades. Trabalhar com a lei é discutir as raízes formadoras da nacionalidade, os projetos, a escrita, seu lugar de enunciação, a sociedade, o outro, as diferenças, o respeito, identidades, memória e a própria história. Para tanto, é preciso uma "mudança de mentalidade" conforme o parecer CNE/CP 1/2004.

Para Goodson, "o currículo escrito proporciona um testemunho, uma fonte documental, um mapa do terreno sujeito a modificações; constitui também um dos melhores roteiros oficiais para a estrutura institucionalizada da escolarização" (GOODSON, 1995: p.21). Deste modo, o currículo é representativo e testemunho oficial das transformações que se amoldam na sociedade brasileira. Oferece, portanto, um mapa com os vestígios para que entendamos melhor a sociedade que o produz e que acaba sendo produzida por ele.A partir da compreensão do seu processo de fabricação é possível situar os conflitos, rupturas e continuidades.

\section{Considerações Finais}

Deste modo, concluímos que é necessário ampliar as discussões sobre as africanidades e afrodescendência no âmbito da formação inicial. Tendo em vista que essa amostra de um universo maior aponta que a universidade piauiense ainda permanece como um espaço privilegiado de reprodução do eurocentrismo e suas hegemonias. E, com base na teoria de JörnRüsen (2001), percebemos que a universidade, do ponto de vista da formação inicial de historiadores e dos professores de história, não foi capaz de realizar a passagem da carência de orientação à teoria da história. Portanto permanece o caldo cultural da carência e das ausências mesmo com uma vasta publicação voltada para a temática do ensino e das 
relações étnico-raciais e ações governamentais que tem incentivado grandes e importantes publicações com aportes teórico-metodológicos para as devidas tratativas das temáticas. Isso repercute negativamente na propagação de uma história nacional de uma comunidade imaginada que não identifica o negro como sujeito e suas contribuições, dando continuidade a uma cadeia estruturada na sociedade de subalternização. Contudo, ainda no ambiente acadêmicos há movimentos importantes voltados para a formação continuada com destaque para o Núcleo Estudos e Pesquisas Afro (NEPA) na UESPI, Núcleo de Pesquisa Sobre Africanidades e Afrodescendência (IFARADA) e o Núcleo de Estudos Roda Griô GEAfro (Gênero, Educação, Afrodescendência) na UFPI. Estes núcleos marcam a ação do movimento negro local, que por sua vez estabelecem relações com o ensino de história no Piauí contribuindo para a passagem da carência de orientação para a formação da consciência histórica no cenário educacional do Estado.

Este estudo mostra ainda que é latente a necessidade de se repensar o que se ensina e como se ensina, de modo a garantir um ensino pluriforme e polifônico por meio de diferentes histórias e vivências. $E$, também que deve haver um maior investimento na formação de professores com a ampliação de disciplinas que permitam um contato com história da África e da história e cultura afro-brasileiras, iluminando sujeitos históricos que resistiram, lutaram e criaram. E com todos os desafios postos às africanidades e afrodescendências é possível perceber "mudança de postura" como propõe as Diretrizes Curriculares Nacionais para a Educação das Relações Étnico-Raciais. Afinal, não é tarefa fácil irromper com séculos de sedimentação e narrativas que colocam em evidência o etnocentrismo europeu aindacomo única matriz da nossa cultura, sociedade e educação.

\section{Referências bibliográficas}

BOURDIEU, Pierre. Homo academicus. Florianópolis: Ed. da UFSC, 2011.

COELHO, Mauro Cezar; COELHO, Wilma de Nazaré Baía. A Lei n 10.639/03 e consciência histórica: ensino de História e os desafios da Diversidade. In: XXVII Simpósio Nacional de História - Conhecimento Histórico e Diálogo Social, 2013, Natal. Lugares dos Historiadores - velhos e novos desafios, 2013.

GINZBURG, Carlo. Mitos, emblemas e sinais. morfologia e história. São Paulo: Companhia das Letras, 1989 
GOMES, Nilma Lino; AMÂNCIO, Iris Maria da Costa (Orgs.). Literaturas africanas e afro-brasileira na prática pedagógica. Belo Horizonte: Autêntica, 2008.

GOODSON, Ivor F. Currículo: Teoria e História. 2. ed. Rio de Janeiro: Vozes, 1995.

LIMA, Mônica. Fazendo soar os tambores: o ensino de História da África e dos Africanos no Brasil. Cadernos PENESB. EdUFF: v. 1, 2000, p. 159-173.

LIMA, Mônica. História da África. In: Cadernos PENESB. EdUFF: n.12, 2010. p. 23-68.

PAULA, Benjamin Xavier de; GUIMARAES, Selva. 10 anos da lei federal $n^{\circ}$ 10.639/2003 e a formação de professores: uma leitura de pesquisas científicas. Educ. Pesqui., São Paulo, v. 40, n. 2, p. 435-448, jun. 2014. Disponível em <http://www.scielo.br/scielo.php?script=sci_arttext\&pid=S1517-

97022014000200009\&lng=pt\&nrm=iso >. Acesso em 16 mai. 2018

PEREIRA, Junia Sales. Diálogos sobre o exercício da docência: A recepção das Leis 10639/2003 e 11645/2008. Revista Educação e Realidade, Porto Alegre, v. 36, n. 1, p. 147-172, jan./abr., 2011. Disponível em: http://www.seer.ufrgs.br/educacaoerealidade/article/viewFile/15073/11515 >. Acesso em: 21 nov. 2017.

PÉREZ RINGUELET, Silvia. Entrevista al profesor Jacques Le Goff. Boletín de Historia Social Europea. 1991 núm. 3, p.57-68. En Memoria Académica. Disponível em: http://www.memoria.fahce.unlp.edu.ar/art_revistas/pr.2420/pr.2420.pdf < acesso em 05 set 2017.

RÜSEN, Jörn. Razão histórica: Teoria da história: fundamentos da ciência histórica. Brasília: UnB, 2001.

\section{Fontes:}

BRASIL. Lei 10.639/2003, de 9 de janeiro de 2003. Altera a Lei n 9. 394, de 20 de dezembro de 1996. Diário Oficial da União, Poder Executivo, Brasília. Disponível em: < http://www.planalto.gov.br/ccivil_03/leis/2003/L10.639.htm> acesso em 18 out 2017.

BRASIL. Lei 11.645/2008, de 8 de março de 2008. Altera a Lei no 9.394, de 20 de dezembro de 1996, modificada pela Lei $n^{\circ}$ 10.639, de 9 de janeiro de 2003, que estabelece as diretrizes e bases da educação nacional, para incluir no currículo oficial da rede de ensino a obrigatoriedade da temática "História e Cultura Afro-Brasileira e Indígena". Diário Oficial da União, Poder Executivo, Brasília.

BRASIL, Ministério Da Educação. Diretrizes Curriculares Nacionais para a Educação das Relações Étnico-Raciais e para o Ensino de história e Cultura Afro-Brasileira e Africana. Resolução CNE/CP 1/2004, de 17 de junho de 2004. Disponível em: > http://portal.mec.gov.br/cne/arquivos/pdf/res012004.pdf<. Acesso em junho de 2017. 
BRASIL, Ministério Da Educação. Parecer CNE/CP 3/2004, de 10 de março de 2004. Disponível em: > http://portal.mec.gov.br/dmdocuments/cnecp_003.pdf <. Acesso em junho de 2017.

BRASIL. Ministério Da Educação. Parâmetro Curricular Nacionais. Pluralidade Cultural. Secretaria de educação fundamental. DF, 1997. Disponível em: > http://portal.mec.gov.br/seb/arquivos/pdf/pluralidade.pdf < acesso em 09/6/2017.

BRASÍLIA. Decreto Federal $n^{\circ}$ 91.851. Autoriza o funcionamento dos cursos de Pedagogia, Ciências, Letras e Administração do Centro de Ensino Superior do Piauí. 1985.

COORDENAÇÃO DO CURSO DE GRADUAÇÃO EM HISTÓRIA. Manual Acadêmico Do Curso De História. Teresina (PI). 2017.

PIAUÍ. Projeto Pedagógico de Curso de História-UESPI. Teresina: Curso de História, 2006.

2012

Projeto Pedagógico de Curso de História-UESPI. Teresina: Curso de História,

Projeto Pedagógico de Curso de História-UESPI. Teresina: Curso de História, 2015.

PIAUÍ. Proposta De Ajuste Curricular - UFPI. Teresina: Curso de História, 2000.

PIAUÍ. Projeto Pedagógico de Curso de História-UFPI. Teresina: Curso de História, 2007. 2011.

Projeto Pedagógico de Curso de História-UFPI. Teresina: Curso de História,

PIAUÍ. Lei Estadual no 3.967. Autoriza o poder executivo a instituir a fundação de apoio ao desenvolvimento da educação do estado do Piauí - FADEP, 1984.

PIAUÍ. Projeto Pedagógico de Curso do Curso de especialização á distância (ead) em História e Cultura Afro-Brasileira E Africana. Teresina da UESPI: Curso de especialização, 2013.

Lucas Rafael Santos Costa:Especialista em Políticas Públicas de Gênero e Raça (UFPI). Mestrando pelo Programa de Pós-Graduação em História do Brasil da Universidade Federal do Piaú (PPGHB/UFPI). Professor de História da Rede Estadual de Ensino Médio do Piauí (Seduc/PI). 
Pedro Pio Fontineles Filho: Doutor em História Social pela (UFC). Mestre e especialista em História do Brasil pela UFPI. Professor Colaborador do Programa de Pós-Graduação em História do Brasil (PPGHB/UFPI). Professor do Curso de História UESPI/CCM.

\section{Como citar este artigo (Howto cite thisarticle):}

COSTA, Lucas Rafael Santos; FONTINELES FILHO, Pedro Pio. Homo Academicus. as africanidades e afrodescendências nos cursos de história da UFPI e UESPI. In REVISTA TRANSVERSOS. "Dossiê: Histórias e Culturas Afro-Brasileiras e Indígenas 10 anos da Lei 11.645/08". Rio de Janeiro, n. 13, MAI-AGO, 2018, pp. 102-122. Disponível em: <http://www.e-publicacoes.uerj.br/index.php/ transversos>. ISSN 2179-7528. DOI:10.12957/transversos.2018.35658.

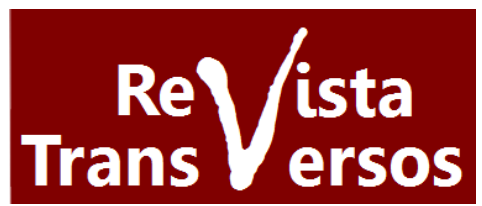

